\title{
Research Paper: Role of Positive Thinking and Personality Traits in Predicting Satisfaction With Nasal Surgeries
}

\author{
Sattar Mahmoudi $^{1^{*}}$ (D), Rasoul Gheisari² ${ }^{2}$, Mehrnosh Rabbanizadeh ${ }^{3}$
}

1. Department of Oral and Maxillofacial Surgery, School of Dentistry, Yasuj University of Medical Sciences, Yasuj, Iran 2. Department of Oral and Maxillofacial Surgery, School of Dentistry, Shiraz University of Medical Sciences, Shiraz, Iran 3. Department of Psychology, Faculty of Humanity, Shiraz Branch, Islamic Azad University, Shiraz, Iran.

$\begin{gathered}\text { Use vour device to scan } \\ \text { and read the article online }\end{gathered}$
Cittion Mahmoudi S, Gheisari R, Rabbanizadeh M. Role of Positive Thinking and Personality Traits in Predicting Satisfac-
tion With Nasal Surgeries. Journal of Research \& Health. 2021; 11(1):45-52. http://dx.doi.org/10.32598/JRH.11.1.1632.1

\section{(c) (1) (5)}

Article info:

Received: 24 Dec 2018

Accepted: 11 May 2019

Publish: 01 Feb 2021

\section{Keywords:}

Positive thinking, Personality traits, Satisfaction, Nasal surgeries, Rhinoplasty

\section{A B STRACT}

Background: Rhinoplasty is recognized as a complicated, but common procedure. Although patient satisfaction with these surgeries is less commonly discussed, it is one of the most important determinants of surgical success. This study was done to predict the patients' satisfaction with nasal surgeries, based on their personality traits and positive thinking.

Methods: This cross-sectional, descriptive, correlational study was conducted in Shiraz, Iran, during the fall and winter of 2017. A total of 200 individuals undergoing rhinoplasty were selected, using the convenience sampling method. The Rhinoplasty Outcome Evaluation-Revised (ROE-R) questionnaire, Automatic Thoughts Questionnaire-Positive (ATQ-P), and NeuroticismExtraversion-Openness (NEO) personality inventory were used for data collection. The obtained results were analyzed by SPSS V. 23, using inferential statistics and stepwise regression analysis.

Results: The results showed that satisfaction with nose fitness had a significant positive relationship with agreeableness and openness $(\mathrm{P}<0.01)$. Also, the overall satisfaction with surgery had a significant positive relationship with these personality traits, while a significant negative relationship was found with neuroticism $(\mathrm{P}<0.01)$. Moreover, the results showed that positive thinking and personality traits could predict $6 \%$ of changes in the overall satisfaction with surgery $(\mathrm{P}<0.001)$. Neuroticism showed an inverse correlation with satisfaction $(\mathrm{P}=0.001, \beta=-0.24)$.

Conclusion: Regarding the relationship between satisfaction with rhinoplasty and personality traits, it was found that different personality traits are associated with different attitudes, influencing surgical outcomes, and satisfaction.

\footnotetext{
* Corresponding Author: Sattar Mahmoudi, PhD.

Address: Department of Oral and Maxillofacial Surgery, School of Dentistry, Yasuj University of Medical Sciences, Yasuj, Iran. Phone: +98 (917) 3039844

E-mail: satardentistry@gmail.com
} 


\section{Introduction}

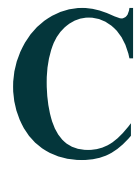

osmetic surgery is one of the most common surgical procedures around the world. In Iran, cosmetic surgeries, particularly nasal surgery or rhinoplasty, is a common procedure. Today, it is recognized as one of the most frequently used cosmetic surgeries in Iran, with the number of candidates increasing every day [1]. In 2015, the International Society of Aesthetic Plastic Surgery (ISAPS) [2] reported around 850,000 rhinoplasty surgeries worldwide.

Research shows that psychological factors play an important role in the increasing trend of cosmetic surgeries [3]. According to previous research, psychological distress influences the person's expectations of cosmetic surgeries and postoperative outcomes [4]. However, it is very difficult to screen the patient's satisfaction with surgery to evaluate the aesthetic parameters of rhinoplasty. Overall, the level of patient satisfaction depends on his/her personality, psychological characteristics, occupation, social needs, and mental state (e.g. depression and physical problems). It has been shown that the surgeon's aesthetic understanding and ability to make the necessary changes are important in increasing patient satisfaction [5].

As mentioned earlier, personality is one of the factors influencing the patient's satisfaction with rhinoplasty. Certain psychological and personality traits are believed to predict the likelihood of cosmetic surgery and its poor or favorable outcomes [6]. To assess personality traits in this area, many studies, using standardized Minnesota Multiphasic Personality Inventory (MMPM-3) and Millon Clinical Multiaxial Inventory (MCMI-II), have shown obsessive-compulsive and narcissistic personality traits in those undergoing nasal surgery [7].

Severe symptoms of obsessive-compulsive disorder, depression, interpersonal difficulties, psychosis, paranoia, fear, and psychiatric problems have been demonstrated in research on people undergoing rhinoplasty [8]. Researchers using MMPI-3 reported that none of the candidates were schizoid, self-centered, schizotypal, or paranoid. Also, no personality disorders, exogenous depression, somatization disorder, depressive disorder, anxiety disorder, alcohol or drug dependence, posttraumatic stress disorder, or delusional disorder was reported in the candidates. Nevertheless, manic disorder, major depression, and borderline personality characteristics were observed in $3.3 \%$ of subjects in the case group [9].
Moreover, dependent, histrionic, and narcissistic personality disorders have been observed in individuals undergoing rhinoplasty. Narcissistic personality disorder was significantly more common in this group [9]. Research shows that obsessive-compulsive personality disorder is significantly more common in individuals undergoing rhinoplasty, compared with those with other personality traits [10]. In a previous study, 133 patients (29\%) with facial cosmetic surgeries showed no personality disorder, based on the MMPI test. Narcissistic personality disorder $(25 \%)$ was observed in other subjects, followed by dependent personality disorder $(12 \%)$ and histrionic disorder (10\%); a truly abnormal nose comprised only $1 \%$ of nasal surgeries. In terms of age, the highest frequency of rhinoplasty was reported in educated and more affluent people, aged 15-25 years [11].

Another study using the Neuroticism-ExtraversionOpenness (NEO) questionnaire showed that in addition to higher scores of conscientiousness and neuroticism, people who obtained lower scores of agreeability and openness were more likely to undergo nasal surgery [12]. Moreover, neuroticism in rhinoplasty candidates and agreeableness in the control group were more common than openness and extraversion. In a meta-analysis, all negative predictors of patient satisfaction with cosmetic surgery were examined, and factors, such as male gender, young age, unrealistic expectations, psychological or family distress, obsessive-compulsive personality disorder, and personality disorder, were identified. This study suggested that sociodemographic and psychosocial variables could predict the adverse outcomes of facial cosmetic surgery [13]. In another study, satisfaction with rhinoplasty was significantly associated with personality traits. According to these studies, one of the main factors in postoperative satisfaction with rhinoplasty may be the recognition of the patient's personality traits [14].

Research shows that having positive or negative expectations or attitudes is dependent on personality traits. According to the American Psychological Association (APA), personality refers to "individual differences in patterns of thinking, feeling, and behavior" [15]. Today, positive psychology, as a new branch of psychology, is recognized as the scientific study of human vigor, good health, and happiness [16]. Positive thinking is the way or result of an individual's focus on a positive or constructive phenomenon [17], creating positive expectations to obtain satisfactory results. Several studies have demonstrated that positive thinking, optimism, and pessimism affect not only the individual's perceived health but also his/her health outcomes [18-21]. Optimistic people show stability and confidence in the face of stressful events 
and tend to consider positive opportunities in the future [22]. In other words, optimism is an expectation of positive outcomes [23].

In a previous study, it was found that $75 \%$ of patients were confident that after a nose job, they would have a better appearance [24]. Overall, studies have shown that optimism and positive thinking are influential factors after surgery [25]. In previous research, the most common tools to measure personality traits were based on psychological pathology. However, in the present study, we used the NEO questionnaire, which is not based on psychological pathology [7]. Therefore, this study was done to predict the patients' satisfaction with rhinoplasty, based on their personality traits and positive thinking.

\section{Methods}

This cross-sectional study was performed on a statistical population, consisting of candidates for cosmetic surgery, who were referred to Shahid Rajaee Hospital in Shiraz, Iran, in the autumn and winter of 2017. The inclusion criteria were having minimum education (high school diploma) and being under 25 or over 35 years of age. A total of 200 individuals were recruited in this study via convenience sampling. There was no specific exclusion criterion other than a reluctance to participate in the study. The study objectives were explained to the participants, and written consent was obtained for participation in the study. The information of the questionnaires remained anonymous, and only demographic information, including age, gender, education, occupation, and marital status, was required. All of the questionnaires, used to analyze the data, were valid. First, the researchers used the address and phone number of the participants, who were referred to Shahid Rajaee Hospital of Shiraz, Iran, to gather the necessary information after obtaining the approval of the center's authorities and describing the study objectives to the participants. They were asked to visit the hospital to complete the questionnaires at the specified time. Almost 65 subjects were recruited, and the researchers visited the hospital clinic for periodic visits; it took about three months to complete the questionnaires.

In this study, satisfaction with rhinoplasty, positive thinking, and personality traits were examined using different questionnaires. The Rhinoplasty Outcomes EvaluationRevised (ROE-R) questionnaire, developed by Alsarraf et al. (2000), was used to assess satisfaction with rhinoplasty. The internal validity and reliability of this questionnaire for various plastic surgeries, including rhinoplasty, have been examined in the literature [26]. In 2014, Izu et al. approved the Brazilian version of the ROE question- naire [27]. However, the number of questions seemed insufficient to determine the patient's satisfaction or dissatisfaction, according to the experts' opinion. Therefore, besides the questions included in the questionnaire, other items were added to better understand the patient's satisfaction, according to the experts' opinions.

The ROE-R questionnaire consists of 14 questions, rated on a five-point Likert scale (always $=5$, frequently $=4$, sometimes $=3$, rarely $=2$, and never $=1$ ), with the scores ranging from one to five. After extracting the content of included factors, they were named by three psychologists: 1 . Size observance and symmetry; 2. Symmetry with other components; and 3. Lack of deficiencies. Cronbach's alpha was measured to determine the reliability of this tool. The results showed a Cronbach's alpha of 0.66 for symmetry and 0.75 for satisfaction.

Moreover, the Automatic Thoughts Questionnaire-Positive (ATQ-P), developed by Ingram and Wisnicki, was used in this study [28]. This questionnaire contains 30 questions, rated on a five-point Likert scale (always $=5$, most often $=4$, sometimes $=3$, rarely $=2$, and never $=1$ ). The minimum score of the questionnaire is 30 , and the maximum score is 150 (average score $=90$ ). A total score of above 90 represents the subject's positive thinking; the closer the score is to 150 , the greater positive thinking will be. In Iran, the reliability of this questionnaire was determined based on Cronbach's alpha (0.94) and the split-half method (0.95) [29]. In another study, Cronbach's alpha was calculated to be 0.89 [30]. In the present study, Cronbach's alpha coefficient was 0.75 .

In addition, the NEO Five-Factor Inventory (NEOFFI), developed by Costa and McCrae, was used in this study [31]. This inventory consists of 60 questions assessing five personality traits, including nervousness, extraversion, agreeableness, openness, and conscientiousness. It has five 12-item scales rating on a Likert scale, ranging from "I totally disagree" (score 0) to "I totally agree" (score 4); the score of each scale ranges from 0 to 48 [32]. The NEO-FFI has been standardized in Iran [33]. The alpha coefficients of the scales ranged from 0.71 to 0.83 , and test-retest reliability indicated coefficients of 0.53 to 0.73 . The total score was measured, based on the sum of scores for the individual scales. In the present study, Cronbach's alpha coefficient was 0.72 for nervousness, 0.69 for openness, 0.63 for extroversion, 0.75 for consciousness, and 0.85 for agreeableness.

Multiple regression analysis and Pearson's correlation matrix were used to analyze the data. Descriptive statistics $($ Mean $\pm \mathrm{SD})$ and inferential statistics (Pearson's ma- 
trix correlation and multiple regression analysis) were also measured to evaluate the data. All data analyses were performed using SPSS V. 23.

\section{Results}

According to Table 1, the acceptance of the null hypothesis indicated the normal distribution of data. The demographic variables are presented in Table 2 . The results showed that $12.6 \%$ of women were dissatisfied, and $11.8 \%$ had less than average satisfaction Table 3 . On the other hand, in males, only $5.5 \%$ were dissatisfied with their proportions, and $0.26 \%$ had less than average satisfaction.

The Mean \pm SD of fitness and satisfaction were $53.69 \pm 6.64$ and $49.47 \pm 8.61$, respectively, according to

Table 1. The results of the Kolmogorov-Smirnov test

\begin{tabular}{ccccc}
\hline Variables & Kolmogorov-Smirnov test & Sig. & Result & Status \\
\hline Fitness & 1.26 & 0.08 & Normal & Accepted \\
\hline Satisfaction & -0.92 & 0.37 & Normal & Accepted \\
Positive thinking & 1.29 & 0.07 & Normal & Accepted \\
\hline Neuroticism & 1.11 & 0.17 & Normal & Accepted \\
\hline Extroversion & 1.06 & 0.21 & Normal & Accepted \\
\hline Agreeableness & 0.81 & 0.51 & Normal & Accepted \\
\hline Openness & 1.32 & 0.06 & Normal & Accepted \\
\hline Conscientiousness & 1.23 & 0.10 & Normal & Accepted \\
\hline
\end{tabular}

Table 2. Demographic characteristics of the participants

\begin{tabular}{|c|c|c|}
\hline Variables & Groups & No. (\%) \\
\hline \multirow{2}{*}{ Gender } & Female & $127(63.5)$ \\
\hline & Male & $73(36.5)$ \\
\hline \multirow{5}{*}{ Marital status } & Single & $89(44.5)$ \\
\hline & Married & $111(55.5)$ \\
\hline & High school diploma & 78 (39) \\
\hline & BA & $107(53.5)$ \\
\hline & $\mathrm{MA}$ and $\mathrm{PhD}$. & $15(7.5)$ \\
\hline \multirow{4}{*}{ Occupational status } & Unemployed & $20(10)$ \\
\hline & Employed & $55(27.5)$ \\
\hline & Housewife & $60(30)$ \\
\hline & Self-employed & $65(32.5)$ \\
\hline \multirow{4}{*}{ Age (years) } & $<25$ & $57(27.5)$ \\
\hline & $25-30$ & $91(42)$ \\
\hline & $30-35$ & 38 (19) \\
\hline & $\geq 35$ & $14(7)$ \\
\hline
\end{tabular}


Table 3. Evaluation of satisfaction with rhinoplasty and fitness in men and women

\begin{tabular}{ccc}
\hline \multirow{2}{*}{ Variables } & & No. (\%) \\
\cline { 2 - 3 } & Female & Male \\
\hline Unfitness & $16(12.6)$ & $4(5.5)$ \\
Fitness & $111(87.4)$ & $69(94.5)$ \\
\hline Dissatisfaction & $15(11.8)$ & $19(26)$ \\
\hline Satisfaction & $112(88.2)$ & $54(74)$ \\
\hline
\end{tabular}

MR:

the results presented in Table 4. Regarding the personality traits, the highest and lowest $\mathrm{Mean} \pm \mathrm{SD}$ were related to conscientiousness $(36.28 \pm 6.53)$ and neuroticism (20.04 \pm 6.06$)$, respectively.

As shown in Table 4, there was a significant positive relationship between fitness satisfaction and personality traits of conscientiousness and openness $(\mathrm{P}<0.01)$. Also, the overall satisfaction with surgery had a positive correlation with positive thinking, while it had a significant negative relationship with neuroticism $(\mathrm{P}<0.01)$. However, other personality traits had no significant association with satisfaction or fitness after surgery.

According to the results in Table 5 positive thinking and personality traits could predict $4 \%$ of changes in satisfaction with surgery and fitness $(\mathrm{P}<0.004, \mathrm{df}=198$, $\mathrm{F}=-8.29)$. Also, agreeableness $(\mathrm{P}<0.004$ and $\beta=0.20)$ had a significant positive relationship with satisfaction of fitness. However, other variables could not predict satisfaction with fitness. The present results showed that positive thinking and personality traits could predict $6 \%$ of chang- es in the overall satisfaction with surgery $(\mathrm{P}<0.001)$. In addition, neuroticism had a significant inverse correlation with satisfaction $(\mathrm{P}=0.001, \beta=-0.24)$. Other variables could not predict the overall satisfaction with rhinoplasty.

\section{Discussion}

Regarding satisfaction with rhinoplasty, the proportion of men satisfied with the surgery was higher than women, and the gender difference was significant. However, the average number of women and men was not significantly different regarding the overall satisfaction, and no significant difference was observed. In a study by Abbas et al. young patients and males showed greater satisfaction with surgery, compared with women [34], which is in line with the results of the present study. However, some previous findings are inconsistent with our results, as men were significantly unhappier and more depressed than women [35-37]. These studies show that men expect significant improvements in their romantic or professional relations following rhinoplasty [36].

Table 4. Statistical analysis of research variables

\begin{tabular}{|cccc}
\hline Variables & Mean \pm SD & Skewness & Elongation \\
\hline Fitness & $53.69 \pm 6.64$ & -0.69 & 0.66 \\
\hline Satisfaction & $49.47 \pm 8.61$ & -0.62 & -0.11 \\
\hline Positive thinking & $121.53 \pm 15.37$ & -0.17 & -0.61 \\
\hline Neuroticism & $20.04 \pm 6.06$ & 0.72 & 0.32 \\
\hline Extroversion & $32.45 \pm 6$ & -1.20 & 1.70 \\
\hline Agreeableness & $24.65 \pm 3.68$ & 0.52 & -0.10 \\
\hline Openness & $32.80 \pm 5.49$ & -0.62 & -0.25 \\
\hline Conscientiousness & $36.28 \pm 6.53$ & -0.56 & -0.40 \\
\hline
\end{tabular}


Table 5. Pearson's correlation matrix for determining the correlation of positive thinking and personality traits with satisfaction after nasal surgery

\begin{tabular}{|c|c|c|c|c|c|c|c|c|}
\hline Variables & 1 & 2 & 3 & 4 & 5 & 6 & 7 & 8 \\
\hline Positive thinking & 1 & & & & & & & \\
\hline Neuroticism & $-0.62^{* *}$ & 1 & & & & & & \\
\hline Extroversion & $-0.68^{* *}$ & $0.63^{* *}$ & 1 & & & & & \\
\hline Agreeableness & 0.07 & -0.09 & 0.05 & 1 & & & & \\
\hline Openness & $0.028 * *$ & $-0.57^{* *}$ & $0.54 * *$ & $0.19^{* *}$ & 1 & & & \\
\hline Conscientiousness & $0.28 * *$ & $-0.35 * *$ & $0.45^{* *}$ & 0.06 & $0.26^{* *}$ & 1 & & \\
\hline Fitness & 0.12 & -0.13 & 0.04 & $0.20^{* *}$ & $0.15^{*}$ & 0.06 & 1 & \\
\hline Satisfaction & $0.23 * *$ & $-0.24 * *$ & 0.11 & 0.09 & 0.02 & 0.01 & 0.32 & 1 \\
\hline
\end{tabular}

Freiberg et al. claimed that rhinoplasty is one of the cosmetic surgeries with the lowest level of satisfaction among patients [38]; also, those who could not express their opinion about their transformation were generally dissatisfied [38]. They found that most surgeons and patients were dissatisfied with rhinoplasty [38] and that the greatest number of rhinoplasty surgeries were performed for male and single individuals. On the other hand, another study reported that rhinoplasty increased the client's self-confidence and made him/her feel more attractive for a successful marriage [39]. It is worth mentioning that most candidates were married in the current study. Previous research shows that following rhinoplasty, the satisfaction rate increases with time [36-39]. Therefore, the aesthetic outcomes of rhinoplasty, if performed by skilled and experienced surgeons, are satisfactory and stable over time [5].

The present results showed that satisfaction of fitness had a significant positive relationship with the personality traits of agreeableness and openness. There was also a significant positive relationship between the overall satisfaction with surgery and positive thinking, while there was a significant negative relationship between satisfaction and neuroticism. Because no similar research has been conducted in this area, the consistency or inconsistency of the results should be considered. Some investigations have been carried out to evaluate satisfactionrelated personality traits. Numerous studies have shown that the patient's mental and psychological assessment is one of the most important factors that can affect postoperative outcomes [36-38]. Concerning the five personality traits examined in this study, the personality trait of openness was more marked in the case group than the control group.

Moreover, personality traits of openness and extraversion were more common in patients undergoing rhinoplasty; in other words, they had new ideas and thoughts and sought new ways and experiences [7]. Overall, by improving the appearance, facial cosmetic surgeries, particularly rhinoplasty, can improve one's emotional, spiritual, social, and physical health. It can also enhance one's self-confidence and self-esteem and even improve his/her professional life [6]. It is strongly recommended that patients receive comprehensive information before surgery to overcome the mentioned problems [5].

Based on numerous studies, personality and mentality, including optimism and positive thinking, can influence the patient's satisfaction or dissatisfaction with surgery. However, in the present study, the subject's point of view was not considered, which might have affected the results. For a successful surgery, preoperative assessment can be important in positive thinking and predict the success rate of surgery. We hope that future studies consider this factor in their analyses.

\section{Conclusion}

According to the present results, $12.6 \%$ of women were not satisfied with rhinoplasty, and $11.8 \%$ had less than average satisfaction; only $5.5 \%$ of men were dissatisfied, and $26 \%$ had less than average satisfaction. The overall satisfaction with surgery had a significant positive correlation with positive thinking, while a significant negative relationship was found between satisfaction and neuroti- 
cism. On the other hand, there was no significant relationship between other personality traits and satisfaction or fitness after rhinoplasty. Based on the results, $10 \%$ of changes in the overall satisfaction could be predicted by personality traits and satisfaction or fitness after rhinoplasty. Moreover, neuroticism and positive thinking could reversely and directly predict overall satisfaction, respectively. Nonetheless, other variables could not predict the overall satisfaction with rhinoplasty.

\section{Ethical Considerations}

\section{Compliance with ethical guidelines}

This study was registered in Shiraz, Iran on February 6, 2020 (License No.: 3158178/98).

\section{Funding}

This research did not receive any grant from funding agencies in the public, commercial, or non-profit sectors.

\section{Authors' contributions}

Study design, manuscript preparation: All authors; Data collection and analysis: Sattar Mahmoudi and Mehrnosh Rabbani Zadeh.

\section{Conflict of interest}

The authors declared no conflict of interest.

\section{References}

[1] Hassanpour SE, Heidari A, Moosavizadeh SM, Tarahomi MR, Goljanian A, Tavakoli S. Comparison of aesthetic and functional outcomes of spreader graft and autospreader flap in rhinoplasty. World J Plast Surg. 2016; 5(2):133-8. [PMCID]

[2] Herruer JM, Prins JB, van Heerbeek N, Verhage-Damen GWJA, Ingels KJAO. Does self-consciousness of appearance influence postoperative satisfaction in rhinoplasty? J Plast Reconstr Aesthet Surg. 2018; 71(1):79-84. [DOI:10.1016/j. bjps.2017.08.008] [PMID]

[3] Slevec J, Tiggemann M. Attitudes toward cosmetic surgery in middle-aged women: Body image, aging anxiety, and the media. Psychlo Women Q. 2010; 34(1):65-74. [DOI:10.1111/ j.1471-6402.2009.01542.x]

[4] Asadi M, Salehi M, Sadooghi M, Afkham Ebrahimi A. [Selfesteem and attitude toward body appearance before and after cosmetic rhinoplasty (Persian)]. Iran J Psychiatry Clin Psychol. 2013; 19(1):28-33. http://ijpcp.iums.ac.ir/article-1-2014-en.html
[5] Kotzampasakis D, Mantalos P, Kotzampasakis S, Danias N, Nikolopoulos T. Assessment of aesthetic results of 100 patients who underwent rhinoplasty-rhinoplasty outcome evaluation. Plast Reconstr Surg Glob Open. 2017; 5(9):e1404. [DOI:10.1097/ GOX.0000000000001404] [PMID] [PMCID]

[6] Zojaji R, Keshavarzmanesh M, Arshadi HR, Mazloum Farsi Baf M, Esmaeelzadeh S. Quality of life in patients who underwent rhinoplasty. Facial Plast Surg. 2014; 30(5):593-6 [DOI:10.1055/s-0034-1393699] [PMID]

[7] Masoudzadeh A, Karkhaneh Yousefi M, Tirgiri A. [A Comparison of personality pattern and general health condition between individuals seeking cosmetic nose surgery and those of the control group (Persian)]. Daneshvar Med. 2009; 16(3):53-8. http:// daneshvarmed.shahed.ac.ir/article_1337.html?lang=en

[8] Naraghi M, Atari M. Comparison of patterns of psychopathology in aesthetic rhinoplasty patients versus functional rhinoplasty patients. Otolaryngol Head Neck Surg. 2015; 152(2):244-9. [DOI:10.1177/0194599814560139] [PMID]

[9] Zojaji R, Arshadi HR, Keshavarz M, Mazloum Farsibaf M Golzari F, Khorashadizadeh M. Personality characteristics of patients seeking cosmetic rhinoplasty. Aesthetic Plast Surg. 2014; 38(6):1090-3. [DOI:10.1007/s00266-014-0402-7] [PMID]

[10] Ghalehbandi MF, Afkham Ebrahimi A. [Personality patterns in cosmetic rhinoplasty patients (Persian)]. IJPCP. 2004; 9(4):4-10. http://ijpcp.iums.ac.ir/article-1-144-en.html

[11] Shahbazi Z, Ardalan H, Maleki M. Aesthetics of numerical proportions in human cosmetic surgery. World J Plast Surg. 2019; 8(1):78-84. [DOI:10.29252/wjps.8.1.78] [PMID] [PMCID]

[12] Swami V, Chamorro-Premuzic T, Bridges S, and Furnham A. Acceptance of cosmetic surgery: Personality and individual difference predictors. Body Image. 2009; 6(1):7-13. [DOI:10.1016/j. bodyim.2008.09.004] [PMID]

[13] Herruer JM , Prins JB, van Heerbeek N, Verhage-Damen GWJA, Ingels KJA. Negative predictors for satisfaction in patients seeking facial cosmetic surgery: A systematic review. Plast Reconstr Surg. 2015; 135(6):1596-605. [DOI:10.1097/ PRS.0000000000001264] [PMID]

[14] Zojaji R, Javanbakht M, Ghanadan A, Hosien H, Sadeghi H. High prevalence of personality abnormalities in patients seeking rhinoplasty. Otolaryngol Head Neck Surg. 2007; 137(1):83-7. [DOI:10.1016/j.otohns.2007.02.027] [PMID]

[15] Vahia VN. Diagnostic and statistical manual of mental disorders 5: A quick glance. Indian J Psychiatry. 2013; 55(3):220-3. [DOI:10.4103/0019-5545.117131] [PMID] [PMCID]

[16] Dastghyb SM, Alizadeh H, Farokhy NA. [The impact of positive thinking skills on creativity in the first year high school female students (Persian)]. J Innov Creat Human Sci. 2012; 1(4):117. http://journal.bpj.ir/article_523724.html?lang=en

[17] Kato K, Zweig R, Schechter CB, Barzilai N, Atzmon G. Positive attitude toward life, emotional expression, self-rated health, and depressive symptoms among centenarians and near-centenarians. Aging Ment Health. 2016; 20(9):930-9. [DOI:10.1080/136078 63.2015.1056770] [PMID] [PMCID]

[18] Peterson C, Seligman ME. Causal explanations as a risk factor for depression: Theory and evidence. Psychol Rev. 1984; 91(3):347-74. [DOI:10.1037/0033-295X.91.3.347] [PMID] 
[19] Peterson C, Seligman ME, Vaillant GE. Pessimistic explanatory style is a risk factor for physical illness: A thirty-fiveyear longitudinal study. J Pers Soc Psychol. 1988; 55(1):23-7. [DOI:10.1037/0022-3514.55.1.23] [PMID]

[20] Shahriyar H. Four affecting factors of adolescent self-esteem [Internet]. 2008 [Updated 2008 June 16].Available from: http:/ / ezinearticles.com/?four-affecting-factors-ofadolescent-self-esteem\&id=1253296

[21] Chang EC. Distinguishing between optimism and pessimism: A second look at the optimism neuroticism hypothesis. In Hoffman RR, Sherrik MF, Warm JS, editors. Viewing psychology as a whole: The integrative science of William N. Dember Washington, D. C: American Psychological Association; 1998. [DOI:10.1037/10290-019]

[22] Mehafarid M, Khakpour M, Jajarmi M, Alizadeh Mousavi A. [Effectiveness of positive thinking training on hardiness \& resilience and Job burnout in women nurses (Persian)]. J Nurs Educ. 2015; 4(1):72-83._https://vlibrary.emro.who.int/imemr/ effectiveness-of-positive-thinking-training-on-hardiness-andresilience-and-job-burnout-in-women-nurses-2/

[23] Scheier MF, Carver CS. Optimism, coping, and health: Assessment and implications of generalized outcome expectancies. Health Psychol. 1985; 4(3):219-47. [DOI:10.1037/02786133.4.3.219] [PMID]

[24] Pereira Filho GDA, Valiati AA, Minuzzi ACS, Cunha TF, Pires JA, Garcia AC, et al. Assessment of long-term patient satisfaction after rhinoplasty performed at the Plastic Surgery Department of Santa Casa de Misericórdia de Porto Alegre Rev Bras Cir Plást. 2011; 26(4):618-23. [DOI: 10.1590/S198351752011000400014]

[25] Hessler JL, Moyer CA, Kim JC, Baker SR, Moyer JS. Predictors satisfaction with facial plastic surgery results of a prospective study. Arch Facial Plast Surg. 2010; 12(3):192-6. [DOI:10.1001/archfacial.2009.69] [PMID]

[26] Alsarraf R, Larrabee Jr WF, Anderson S, Murakami CS, Johnson Jr CM. Measuring cosmetic facial plastic surgery outcomes: A pilot study. Arch Facial Plast Surg, 2001; 3(3):198-201. [DOI:10.1001/archfaci.3.3.198] [PMID]

[27] Izu SC, Kosugi EM, Lopes AS, Brandão KV, Sousa LBG, Suguri VM, et al. Validation of the rhinoplasty outcomes evaluation (ROE) questionnaire adapted to Brazilian Portuguese. Qual Life Res. 2014; 23(3):953-8. [DOI:10.1007/s11136-0130539-x] [PMID]

[28] Ingram RE, Wisnicki KS. Assessment of positive cognition. J Conslt Clin Psychol. 1988; 56(6):898-902. [DOI:10.1037/0022006X.56.6.898]

[29] Ghavidel S, Gilouri A. Librarians and positive thinking skills case study central libraries of universities covered by the Ministry of Science, Research and Technology (MSRT) in Tehran. Int J Inf Manage. 2016; 14(2):47-57. https://ijism. ricest.ac.ir/index.php/ijism/article/view/790

[30] Ghaffari Monfared M, Naderi F. Relationship between religious attitude, optimism, spiritual intelligence and mental hygiene of post-graduate students of Islamic Azad University Tehran Science and Research Branch. Mediterr J Soc Sci. 2015; 6(6 S1):208-13. [DOI:10.5901/mjss.2015.v6n6s1p208]

[31] Casta Jr PT, McCrae RR. NEO PI- R Professional manual. Odessa, FL: Psychological Assessment Resources; 1992. http://www.sjdm.org/dmidi/NEO_PI-R.html
[32] Amini L, Heidary M, Daneshparvar H. Personality traits and their impacts on the mental health of battered women. J Midwifery Reprod Health. 2015; 3(2):349-54. [DOI: 10.22038/ jmrh.2015.3966]

[33] Haghshenas H. [Persian version and standardization of NED personality inventory-revised (Persian)]. IJPCP. 1999; 4(4):38-48. http://ijpcp.iums.ac.ir/article-1-1757-en.html

[34] Abbas OL. Revision rhinoplasty: Mdictive factors. Springerplus. 2016; 5(1):1472. [DOI:10.1186/s40064-016-3166-5] [PMID] [PMCID]

[35] Khansa I, Khansa L, Pearson GD. Patient satisfaction after rhinoplasty: A social media analysis. Aesthet Surg J. 2016; 36(1):NP1-5. [DOI:10.1093/asj/sjv095] [PMID]

[36] Slator R, Harris DL. Are rhinoplasty patients potentially mad?. Br J Plast Surg. 1992; 45(4):307-10. [DOI:10.1016/00071226(92)90058-6]

[37] Izu SC, Kosugi EM, Brandão KV, Lopes AS, Sousa Garcia LB, Suguri VM, et al. Normal values for the rhinoplasty outcome evaluation (ROE) questionnaire. Braz J Otorhinolaryngol. 2012; 78(4):76-9. [DOI:10.1590/S1808-86942012000400015] [PMID]

[38] Hashemi SAG, Edalatnoor B, Edalatnoor B, Niksun O. A comparison of body image concern in candidates for rhinoplasty and therapeutic surgery. Electron Physician. 2017; 9(9):5363-8. [DOI:10.19082/5363] [PMID] [PMCID]

[39] Sarwer DB, Infield AL, Baker JL, Casas LA, Glat PM, Gold $\mathrm{AH}$, et al. Two-year results of a prospective, multi-site investigation of patient satisfaction and psychosocial status following cosmetic surgery. Aesthet Surg J. 2008; 28(3):245-50. [DOI:10.1016/j.asj.2008.02.003] [PMID] 